\title{
Etkileşimli Kitap Okuma: Dil ve Erken Okuryazarlık Becerilerinin Geliştirilmesinde Etkili Bir Yöntem*
}

\author{
Cevriye Ergül** \\ Ankara Üniverstesi
}

\author{
Ayşe Dolunay Sarıca*** \\ Dokuz EylülÜniversitesi
}

\author{
Gözde Akoğlü*** \\ Kırıkkale Üniversitesi
}

\begin{abstract}
Öz
Erken okuryazarlık, çocukların okul öncesi dönemde okuma ve yazmaya ilișkin kazanmaları gereken önkoşul bilgi, beceri ve tutumları içermektedir. Yapılan birçok çalışmada erken okuryazarlık becerilerinin gelecekteki okuma yazma ve akademik becerileri güçlü bir şekilde yordadığı gösterilmiştir. Araştırmalardan elde edilen sonuçlar kısa ve uzun dönemde okul başarısı üzerinde etkili olduğu gözlenen erken okuryazarlık becerilerinin, okul öncesi dönemde desteklenmesi gerektiğini ortaya koymaktadır. Yetişkinlerin ev ve okul ortamlarında çocuklarla gerçekleştirdikleri birlikte kitap okuma etkinlikleri de, erken okuryazarlık becerilerinin desteklenmesinde en sık kullanılan müdahale yöntemlerinden birisidir. Alanyazında, yetişkinin çocuğa yönelik öğretici davranışlarını içeren kitap okuma etkinliklerinin, çocukların dil gelişimleri üzerinde etkili olduğu gösterilmiștir. Bu bağlamda geliștirilen ve yetișkin ile çocuk arasında etkin bir iletișimi temel alan Etkileşimli Kitap Okuma (EKO) uygulamaları ise yetişkinin okuma sırasında aktif dinleyici konumunda olması, çocuğa öykü ile ilgili sorular yönelterek konuşma fırsatları sağlaması, bilinmeyen sözcükleri tanımlaması ve çocuktan gelen yanıtları tekrarlayarak genişletmeler yapması bakımından geleneksel uygulamalardan farklılaşmaktadır. Çok sayıda çalıșmada EKO'nun çocukların dil, erken okuryazarlık becerileri ve okumaya yönelik tutumları üzerindeki olumlu etkilerinin olduğu ve gelişen bu becerilerin akademik başarıya önemli katkılarının olduğu gösterilmiştir. Bu noktadan hareketle bu yazıda, EKO yöntemi ele alınmış ve uygulama adımlarına ilişkin bilgi verilmiştir.
\end{abstract}

Anahtar sözcükler: Erken okuryazarlık, okul öncesi dönem, etkileşimli kitap okuma

\footnotetext{
*Bu çalışma TÜBİTAK tarafından desteklenen 111 K161 nolu proje kapsamında yürütülmüştür.

${ }^{* *}$ Sorumlu Yazar: Doç. Dr., Ankara Üniversitesi, Eğitim Bilimleri Fakültesi, Özel Eğitim Bölümü, Ankara, E-Posta: cergul@ankara.edu.tr

${ }^{* * *}$ Yard. Doç. Dr., Dokuz Eylül Üniversitesi, Buca Eğitim Fakültesi, Özel Eğitim Bölümü, İzmir, E-Posta: dolunaysarica@gmail.com

***** Doç. Dr., Kırıkkale Üniversitesi, Sağlık Bilimleri Fakültesi, Çocuk Gelişimi Bölümü, Kırıkkale, E-Posta: gakoglu@kku.edu.tr
} 


\title{
Dialogic Reading: An Effective Method to Improve Language and Early Literacy Skills
}

\begin{abstract}
Early literacy includes prerequisite knowledge, skills, and attitudes that children should acquire in relation to reading and writing prior to primary education. Several studies have shown effectiveness of early literacy skills on later reading and writing skills and academic achievement. Results reveal that early literacy skills that have been found to have an impact on short-and long-term school success need to be supported in early childhood. Adult-child joint reading activity is one of the most commonly used methods of intervention in promoting early literacy skills. There are many studies demonstrating that adult child joint reading activities, particularly those in which adults display instructive behaviors are highly effective on children's language development. Dialogic Reading (DR) is one technique that differs from traditional adult-child shared book reading in that during DR, the adult takes the role of an active listener, gives the child opportunities to talk by asking questions, defines unknown words and repeats and extends child's verbal responses during reading. Numerous studies show DR's significant effects on preschoolers' language, early literacy skills and reading attitudes as well as future academic performance. The aim of this paper was to introduce DR as an effective shared book reading method.
\end{abstract}

Keywords: Early literacy, preschool, dialogic reading

Okuma ve yazma, bireylerin yaşamları boyunca yakın ve uzak çevrelerine ilişkin bilgi edinmede ve kendini diğerlerine ifade etmede en sık kullandıkları iletişim araçlarından biridir. Bu nedenle tüm çocukların ilkokul çağına denk gelen bilişsel ve fiziksel olgunlaşmayla birlikte okuma yazmayı öğrenmeleri beklenmektedir. $\mathrm{Bu}$ öğrenme sürecinin ne derece hızlı ve etkili geliştiği ise, çocuğun özellikle okula başladığ 1 dönemdeki hazır bulunuşluğu ve sahip olduğu okuma yazmaya ilişkin önkoşul bilgi ve beceri düzeyleri ile yakından ilişkilidir. Bu bağlamda, erken okuryazarlık olarak ifade edilen ve "formel okuma ve yazma öğretimi öncesinde çocukların sahip olmaları gereken tüm bilgi, beceri ve tutumlar” şeklinde tanımlanan kavram (Sulzby ve Teale, 1991; Uzuner, 1997; Whitehurst ve Lonigan, 1998) okuma başarısının en güçlü yordayıcılarından biri olarak kabul edilmektedir. Buna bağlı olarak da eğitim alanında son 20-30 yılın en çok konuşulan ve çalışılan konulardan biri olarak karşımıza çıkmaktadır.

Erken okuryazarlık sözel dil, sözcük dağarcı̆̆ı, sesbilgisel farkındalık, yazı farkındalığı ve harf bilgisi alanlarını kapsamaktadır (Aarnoutse, Leeuwe ve Verhoeven, 2005; Casey ve Howe, 2002; Dickinson ve McCabe, 2001; Elliott ve Olliff, 2008; Neuman ve Dickinson, 2001; Spira, Bracken ve Fischel, 2005; Whitehurst ve Lonigan, 2001). Görüldüğü gibi erken okuryazarlık, okuma yazmayı okul öncesi dönemde öğrenmekten ziyade, ilköğretimde okuryazarlığa kolay bir geçiş yapabilmek için çocuğun okul öncesinde kazanması gereken önkoşul becerileri içermektedir.

Erken okuryazarlık becerileri ile akademik başarı arasındaki ilişki çok sayıda çalışmada incelenmiş ve iki grup değişken arasında oldukça güçlü ilişkiler olduğu bulunmuştur. Örneğin pek çok araştırma, ilkokuldaki okuma başarısının okul öncesi dönemdeki sözcük bilgisi (Armbruster, Lehr ve Osborne, 2003; Beck, McKeown ve Kucan, 2002; Greene ve Lynch-Brown, 2002; Hart ve Risley, 2003), sesbilgisel farkındalık (Griffith ve Olson, 1992; Lundberg, Frost ve Petersen, 1988; Maclean, Bryant ve Bradley, 1987; Yopp ve Yopp, 2000), yaz1 farkındalığı (Lesiak, 1997; Lomax ve McGee, 1987; Pullen ve Justice, 2003; Riley, 1996) ve harf bilgisi 
(Badian, 1995; Denton ve West, 2002; Riley, 1996) ile yakından ilişkili olduğunu göstermektedir. Çok sayıda boylamsal çalışmada ise erken okuryazarlık becerilerinin ilkokul, ortaokul ve lise dönemlerindeki akademik başarıyı da güçlü bir şekilde yordadığı bulunmuştur (Cunningham ve Stanovich 1997; Dickinson ve McCabe, 2001; Juel, 1988, Spira ve diğ., 2005; Stevenson ve Fredman, 1990). Erken okuryazarlık becerilerinin özellikle ilk okuma yazmayı öğrenme sürecinde çok önemli olduğu ve erken okuryazarlık becerileri gelişmiş çocukların bu süreçte daha başarılı oldukları belirtilmektedir (Nelson, 2005; Spira ve diğ., 2005). Başlangıçta yaşanan okuma güçlüklerinin ilerleyen yıllarda da süreklilik gösterdiğini (Cunningham ve Stanovich, 1997; Dickinson ve McCabe, 2001; Scarborough, 2001) ortaya koyan çalışmalar da göz önünde bulundurulduğunda, erken okuryazarlık becerilerinin uzun dönem etkileri olduğu da açıktır.

Diğer taraftan, pek çok araştırmada, sosyo-ekonomik düzeyin (SED) erken okuryazarlık becerilerinin gelişiminde etkili bir değişken olduğu ve bu bağlamda düşük SED’de yer almanın bir risk faktörü oluşturduğu belirlenmiştir (Bursuck ve Damer, 2007; Çakmak ve Yılmaz, 2009; Dickinson ve McCabe, 2001; Foorman, Francis, Fletcher, Schatschneider ve Mehta, 1998; Lonigan ve Whitehurst, 1998; Niklas ve Schneider, 2013; Raz ve Bryant, 1990; Rush, 1999; Stevenson ve Fredman, 1990). Araştırmalar, düşük SED ailelerden gelen çocukların erken okuryazarlık becerilerinin orta ve üst SED'den gelenlere kıyasla daha yetersiz olduğu ve aynı zamanda okul başarılarının da daha düşük olduğunu ortaya koymuştur (Dickinson ve Tabors, 2001; Justice, Invernizzi, Geller, Sullivan ve Welsch, 2005; McCardle, Scarborough ve Catts, 2001; Snow, Burns ve Griffin, 1998; Whitehurst ve Lonigan, 2001).

Araştırmalardan çıkan bu sonuçlar, kısa ve uzun dönemde okul başarısı üzerinde etkili olduğu gözlenen erken okuryazarlık becerilerinin, okul öncesi dönemde desteklenmesi gerektiğini göstermektedir. Yetişkinlerin ev ve okul ortamlarında çocuklarla gerçekleştirdikleri birlikte kitap okuma etkinlikleri ise, erken okuryazarlık becerilerinin desteklenmesinde en sık kullanılan müdahale yöntemlerinden birisidir. Bu alandaki araştırmalar incelendiğinde, okul öncesi dönemde bir yetişkinle rutin olarak birlikte kitap okuma etkinliklerine katılan çocukların dil becerilerinden özellikle ifade edici dil becerileri ve sözcük bilgilerinde akranlarına kıyasla daha başarılı oldukları gözlenmektedir (Armbruster, Lehr ve Osborne, 2003; Beck, McKeown ve Kucan, 2002; Greene ve Lynch-Brown, 2002; Hart ve Risley, 2003; Huebner ve Payne, 2010; Robbins ve Ehri, 1994). Birlikte kitap okuma etkinliklerinin çocuklara yeni sözcükler öğrenmede oldukça etkili bağlamlar yarattığı (Senechal ve Cornell, 1993) ve tek okumada öğrenilemeyen sözcüklerin, kitapların tekrarlı okunmasıyla birlikte çocuklar tarafından kolaylıkla kazanıldığı (Robbins ve Ehri, 1994) öne sürülmektedir.

Tekrarlı okumalara dayalı etkinliklerle birlikte, yetişkinin doğrudan öğretici yaklaşımlarını içeren kitap okuma etkinliklerinin ise, çocukların dil gelişimi üzerinde daha da etkili olduğu gösterilmiştir (Robbins ve Ehri, 1994; Senechal ve Cornell, 1993; Senechal, LeFevre, Thomas ve Daley, 1998). Buna göre, okuma esnasında hedef sözcüklere yönelik sorulara yanıt veren çocukların, yalnızca sözcüğü tekrar edip o sözcüğe karşılık gelen resme işaret eden çocuklara kıyasla daha fazla sözcük öğrenip ürettikleri saptanmıştır (Senechal, 1997; Senechal, Thomas ve Monker, 1995). Bu bulgular çocuğun etkinliğe aktif katılımının ve süreçte artan yetişkin çocuk etkileşiminin, çocuğun öğrenmesi üzerinde olumlu etki bıraktığını göstermektedir.

$\mathrm{Bu}$ sonuçlardan yola çıkılarak Whitehurst ve diğerleri tarafından çocuğun kitap okuma etkinliğine aktif katılımını öngören Etkileşimli Kitap Okuma-Dialogic Reading yöntemi geliştirilmiştir (Whitehurst ve diğ., 1988; Whitehurst, Arnold ve diğ., 1994; Whitehurst, Epstein ve diğ., 1994). Etkileşimli kitap okuma (EKO), çocuğun sözel dil becerilerinin ve sözcük bilgisinin geliştirilmesinin hedeflendiği ve yetişkin ile çocuğun etkileşimli olarak kitap okudukları bir süreci ifade etmektedir (Whitehurst ve diğ., 1988; Whitehurst, Arnold ve diğ., 1994; Whitehurst, Epstein ve diğ., 1994). EKO'da çocuk ve yetişkin rolleri değiştirmekte ve yetişkinin yönlendirmeleriyle çocuk hikâyenin okuyucusu olmayı öğrenmektedir. Yetişkin bu süreçte aktif dinleme ve hikâyeyle ilgili çocuğa soru yöneltme rollerini üstlenir. Yetişkin çocuğa hikayeyle ilgili sorular sorarak ona konuşma firsatları sağlar, bilinmeyen sözcükleri tanımlar ve çocuktan gelen yanıtları tekrarlayarak genişletmeler yapar (Justice ve Pullen, 2003; Whitehurst, Arnold ve diğ., 1994). 
EKO çocukların alıcı ve ifade edici dil becerilerini geliştirmeyi hedefleyen üç temel uygulama prensibine dayanmaktadır. Bunlar, çocuğu okuma etkinliğine katılıma teşvik etme, çocuğa konuştuklarıyla ilgili dönüt verme ve çocuğun ilgi alanlarını yansıtan kitaplar seçerek üzerinde konuşulacak konular belirlemedir (Hargrave ve Senechal, 2000; Justice ve Pullen, 2003; Morgan ve Meier, 2008). Bu uygulamalar çocukların öyküye ilgi duyma, dinlediğini anlama, sözcük dağarcığını geliştirme ve dili uygun şekilde kullanma becerilerini desteklemektedir. Çocuğun okuma etkinliğine aktif katılımı okuma esnasında yetişkinin çocuğun konuşmasını başlatıı bazı teknikler kullanması ile sağlanmaktadır. Whitehurst ve diğerleri (1994) tarafından CROWD olarak kısaltılan bu teknikler; C (completion-tamamlama) çocuğa öyküde bir ifade ya da cümleyi tamamlatma, R (recall-hatırlama) öyküde geçen karakterler ya da olaylarla ilgili sorular sorma, O (open-ended questions-açı uçlu sorular) kitaptaki resimlerde geçen olayları betimletme, W (wh-questions-5N1K soruları) kitabın resimlerinde yer alan bir nesne ya da eylemi isimlendirmesini isteme ve D (distancing-ilişkilendirme) çocuğa hikâyedeki olaylarla kendi yaşamı arasında bağ kurdurma etkinliklerini içermektedir. EKO aynı zamanda çocuğa yapıcı dönüt verme ve yanıtlarını genişletme gibi yetişkin davranışlarını da içermektedir. PEER kısaltmasıyla ifade edilen bu stratejiler ise, P (prompt-yönlendir) konuşma başlatma, E (evaluate-değerlendir) çocuğun yanıtlarının doğruluğunu değerlendirme, E (expand-genişlet) çocuğun yanıtlarını uygun sözcük ya da cümlelerle genişletme ve $\mathrm{R}$ (repeat-tekrarla) çocuktan düzeltilmiş ya da genişletilmiş tepkileri tekrarlamasını isteme olarak tanımlanmaktadır.

Çok sayıda çalışma, farklı gelişimsel özellikler gösteren okul öncesi çocuklarda EKO’nun dil becerileri üzerindeki etkilerini incelemiş̧ir. Normal gelişim gösteren, düşük SED ya da çift dilli olma gibi risk faktörleri taşıyan ve otizm, dil bozuklukları gibi gelişimsel yetersizlikler gösteren okul öncesi çocuklarla gerçekleştirilen müdahale çalışmaları, EKO'nun bu gruplarda yer alan çocukların ifade edici dil başta olmak üzere dil becerilerini anlamlı düzeyde desteklediği yönünde sonuçlara işaret etmekte, ev, okul öncesi sınıf veya her ikisinde birlikte yürütülen 6 ila 8 haftalık bir EKO müdahalesiyle bu sonuçların elde edilebildiğini göstermektedir. Örneğin EKO’yu geliştiren ekibin alt sosyo-ekonomik düzey okul öncesi çocuklarla yürüttüğü etkililik çalışmaları, EKO'nun özellikle ailelerin katılım gösterdikleri deney gruplarındaki çocukların dil becerilerini anlamlı düzeyde desteklediğini göstermiş̧tir (Lonigan ve Whitehurst, 1998; Whitehurst ve diğ., 1994). İlerleyen y1llarda, farklı araştırmacılarca normal gelişim ya da farklı gelişimsel özellikler (iki dillilik, dilde gecikme, otizm spektrum bozukluğu) sergileyen okul öncesi çocuklarla gerçekleştirilen çalışmalar da (Fluery, Miramontez, Hudson ve Schwartz, 2014; Hargrave ve Senechal, 2000; Huennekens ve Xu, 2016; Lever ve Senechal, 2011; Sim, Berthelsen, Walker, Nicholson ve Fielding-Barnsley, 2014; Şimşek ve IşıloğluErdoğan, 2015; Towson ve Gallagher, 2016) söz konusu bulguları desteklemiş̧ir.

EKO ile ilgili araştırmalar, yetişkinin okuma esnasında yazı ve seslere dikkat çektiği durumlarda (örneğin; yazıyı parmakla takip etme ve gösterme, hedef sesbirimlerin sesletimini yapma) çocukların yazı farkındalığ Whitehurst ve Epstein, 1994; Ezell ve Justice, 2000; Justice ve Ezell, 2002; Justice, Kadevarek, Bowles ve Grimm, 2005; Valdez-Menchaca ve Whitehurst, 1992; Whitehurst, Arnold ve diğ., 1994). Çocukların, bu şekilde, yazı ile sözel dil ilişkisini çözümleyebildikleri, yazının özelliklerini kavrayabildikleri ve sözcüklerin sesbilgisel organizasyonunu anlayabildikleri belirtilmekte ve EKO'nun bu şekilde okul öncesi çocukların erken okuryazarlık becerilerinin desteklenmesinde etkili olduğu ifade edilmektedir (Ezell ve Justice, 2000; Justice ve Ezell, 2002).

EKO'nun, çocukların okumaya ilişkin olumlu tutum geliştirmelerinde de etkili olduğu bildirilmektedir (Kotaman, 2008; LaCour, McDonald; Tissington ve Thomason, 2013; Lever ve Senechal, 2011; Sperling ve Head, 2002). Konuşma firsatı tanınan, yetişkin tarafından konuşmaları dikkatle dinlenen, etkinliğin liderliğini üstelenen ve yeni şeyler öğrenen çocuklar keyifli vakit geçirmekte ve geliştirdikleri olumlu duyguları kitaplara ve okumaya da yansıtmaktadırlar. Böylece okumaya karşı olumlu tutum geliştiren çocukların, alanyazında bildirilen okuma tutumu ile okul başarısı arasındaki yakın ilişki doğrultusunda (Kush, Watkins ve Brookhart, 2005), okula başladıklarında akademik başarılarının da daha yüksek olması beklenmektedir. 
Sonuç olarak, EKO'nun çocukların dil, erken okuryazarlık becerileri ve okumaya yönelik tutumları üzerindeki olumlu etkilerinin olduğu ve gelişen bu becerilerin akademik başarıya önemli katkılarının olduğu görülmektedir. Nitekim söz konusu sonuçlar, eğitimcilerin EKO’yu kanıt temelli bir dil ve erken okuryazarlık müdahale yöntemi olarak kabul etmelerine ve uygulamalarda sıklıkla yer vermelerine temel oluşturmuştur (Justice ve Pullen, 2003). Bu bağlamda, risk grubunda olan, özel gereksinimi olan veya normal gelişim gösteren tüm çocukların EKO gibi etkili, gelişimsel olarak uygun, kolay uygulanabilir ve günlük rutinler içerisine kolayca yerleştirilebilen yöntemler ile erken dönemde desteklenmelerinin önemli olduğu rahatllkla ifade edilebilmektedir.

Yukarıda yer alan gerekçeden yola çıkarak, bu çalışmanın yazarları TÜBİTAK destekli bir proje çerçevesinde düşük sosyo-ekonomik ailelerden gelen anasınıfi öğrencilerinin dil ve erken okuryazarlık becerilerinin desteklenmesine yönelik olarak EKO yönteminin etkililiğini incelemişlerdir. Yapılan çalışmanın sonuçları, yabancı alanyazında olduğu gibi, EKO'nun farklı müdahale koşullarında (ev, okul ya da ev+okul uygulamaları) çocukların erken okuryazarlık becerilerini desteklediğini ve çocukların birinci sınıftaki okuma ve okuduğunu anlama performanslarını da artırdığını (Ergül ve diğ., 2016) göstermiştir. Bu çalışmada ise EKO'nun Ergül ve arkadaşları (2016) tarafından gerçekleştirilen etkililik çalışması çerçevesinde uygulandığı şekliyle kapsamlı olarak tanıtılması amaçlanmıştır.

\section{Etkileşimli Kitap Okuma (EKO) Uygulama Adımları}

Yetişkin ve çocuk arasında etkin bir iletişimi temel alan EKO uygulamaları, yetişkin tarafindan çocuklara öykü okunmaya başlamadan önce çocukların katılımcı olmalarını sağlaması ve bu katılımın öykü okuma sırasında ve sonrasında devam etmesini teşvik etmesi bakımından geleneksel uygulamalardan farklılaşmaktadır. EKO uygulamaları okuma öncesi, sırası ve sonrasında gerçekleşen süreçler ile bir bütündür. Büyük grup ve küçük grup uygulamalarının yanı sıra bireysel olarak da gerçekleştirilebilen uygulamalarda, çocuğun/çocukların liderliğinin izlenmesi anahtar rol oynamaktadır. Bu bağlamda, okuma öncesinde, sırasında ve sonrasında EKO uygulama adımlarına değinmekte yarar vardır.

Okuma öncesi EKO uygulama adımları. Okuma öncesi adımların uygun şekilde gerçekleştirilmesi EKO uygulamalarından beklenen düzeyde başarı elde edilmesinde anahtar rol oynamaktadır. Bu nedenle, EKO uygulamalarını gerçekleştirecek kişiye okuma öncesi süreçte önemli sorumluluklar düşmektedir. Bunlardan ilki, EKO uygulamalarını gerçekleştirmeye olanak tanıyacak, nitelikli bir resimli çocuk kitabının seçilmesidir. Çalışılan çocuk grubunun gelişimsel gereksinimlerini karşılayabilecek, biçim ve içerik özellikleri bakımından çocukların içinde bulundukları yaş grubu ile örtüşen kitapların seçilmesi büyük önem taşımaktadır. Bununla birlikte, seçilen kitapların çocukların ilgilerini çekmesi EKO uygulamalarının niteliği açısından son derece önemlidir. Bu nedenle kitap seçiminde, çocukların ilgileri temel alınmalıdır. Belirlenen kitaplarda çocukların yeni öğrendikleri sözcüklerin yanı sıra, henüz tanışmadıkları sözcüklerin de yer almasına dikkat edilmelidir. Bununla birlikte, çocukların dil üretimlerini artıracak nitelikte, dikkat çekici detayların yer aldığı resimleri içeren kitaplar tercih edilmelidir. Uygun bir kitabın seçilmesi, dil ve erken okuryazarlık becerilerinin desteklenmesine yardımcı olacaktır.

Kitap seçiminin ardından, hedef sözcüklerin ve sesbirimlerin belirlenmesi ikinci uygulama adımını oluşturmaktadır. Hedef sözcüklerin ve sesbirimlerin seçiminde çalışılan çocuğun ve/veya çocuk grubunun takvim yaşı kadar gelişimsel özellikleri de belirleyici olmaktadır. Öğrenme kapasitesi göz önünde bulundurularak kullanılacak kitaplarda belirli sayıda sözcüğün öğretimi hedeflenmelidir. Özel gereksinimli çocuklarla çalışılırken belirlenen hedef sözcüklerin sayısı normal gelişim gösteren çocuklara kıyasla daha az olabilirken (sözgelimi, 2-5 sözcük), bu sayı normal gelişim gösteren çocuklarda 5-10 arasında değişebilmektedir. Hedef sözcükler, çocukların yeterince tanımadıkları, henüz edinmedikleri sözcükler arasından seçilmelidir. Böylece yeni sözcüklerin öğrenilmesine firsat tanınmalıdır. Ne var ki EKO'nun, kimi zaman yeni öğrenilen bir sözcüğün anlamının pekiştirilmesi ya da birden fazla anlamı olan bir sözcüğün diğer anlamlarının öğrenilmesi amacıyla da kullanılabileceğini belirtmekte yarar vardır. Hedef sözcük seçiminde isim sözcükler kadar, ortaçlara, 
eylemlere ve deyimlere de yer verilmelidir. Hedef sözcüklerin açıklanmasında çocuk dostu bir anlatım tercih edilmeli, sözcüklerin anlamlarına ilişkin açılamalarda belirsiz ya da soyut ifadelerden mümkün olduğunca kaçınılmalıdır. Hedef sesbirimlerin belirlenmesinde de çocukların mevcut sesbilgisi repertuarları dikkate alınmalı, okunan öyküde hedeflenen sesbirimlerin sözcük içinde farklı konumlarda temsil edilmesini sağlayacak nitelikle birden fazla sözcük olmasına dikkat edilmelidir (sözgelimi hedef sesbirim "m" ise, öyküde yer alan "masa", "yemek", "kalem" sözcüklerinin bu amaçla kullanılması gibi). Yetişkin EKO sırasında hedef sözcüklere ve sesbirimlere ilişkin yapacağı vurguları, soracağı soruları ve hedef sözcüklerin anlamlarına ilişkin yapacağı açıklamaları çocuklara öyküyü okumadan önce belirlemeli, gerekirse ilgili sayfalara yapışkan kâğıtlar ile kendisi için hatırlatmalar yazmalıdır. Çocuklarla birlikte EKO uygulamalarına başlanmadan önce, kitabın bütün olarak incelenmesi, sorulacak soruların ve yapılacak vurgulamaların provasının yapılması, özellikle ilk uygulamalarda kolaylık sağlayacaktır.

EKO uygulamalarının öncesinde yapılacak diğer bir düzenleme de çocukların okuma sırasındaki yerleşimlerinin planlanmasıdır. EKO uygulamaları sırasında çocukların kitabın resimlerini kolayca görebilecekleri ve rahat olabilecekleri bir pozisyonda oturmaları gerekmektedir. Çoğunlukla "U" şeklinde yapılan bir düzenleme bütün çocukların kitabın resimlerini rahat bir şekilde görmelerini sağlamaktadır. Çocukların oturmaları için sandalye ya da minderler kullanılabilir. Yetişkin de çocuklarla aynı hizada olacak ve göz teması kurabilecek şekilde oturmalıdır. Ortamda çocukların dikkatini dağıtabilecek farklı uyaranlar varsa bu uyaranlar ortadan kaldırılmalıdır. Ayrıca, çocukların su ve tuvalet gereksinimlerinin karşılanmış olması uygulamanın bölünme olasılığını ortadan kaldıracak ve çocukların dikkatlerini sürdürmelerini kolaylaştıracaktır.

Çocukların yerleşimleri sağlandıktan sonra yetişkin, kitabı bütün çocukların görebileceği ve kitabın ön kapağı çocuklara dönük olacak şekilde tutmalı ve okuma boyunca kitabın çocuklara dönük olmasına dikkat etmelidir. Bu, çocukların hedef sözcüklerin resimlerini, yazılı uyaranların yer aldığı bölümleri, yazı ve resim arasındaki ilişkileri fark edebilmeleri açısından büyük önem taşımaktadır. Kitabın kapak sayfası çocuklara dönük olacak şekilde başlık yüksek sesle okunmalı ve bir yandan da parmakla gösterilmelidir. Böylece çocukların kitabın başlğ̆ını ve yazının yönünü fark etmeleri sağlanabilir. Ayrıca çocukların, sözcüklerin boşluklar yardımıyla birbirlerinden ayrıldıklarını fark etmeleri açısından da bu tür uygulamalar etkilidir. Yetişkin, kitabın başlığına ve kapak resmine dikkat çekerek kitabın ne hakkında olduğuna ve öyküde ne tür olaylar olabileceğine dair çocuklara açık uçlu sorular (Bu resimde neler görüyorsunuz? Sizce bu kitap ne hakkında olabilir? vb.) yöneltmeli ve çocukların tahminde bulunmalarına olanak tanımalıdır. Bu tür bir yaklaşım, çocukların kendilerini ifade etmeleri ve dili kullanmaları için onları cesaretlendireceği gibi, okunan öykünün sonuna kadar tahminlerinin gerçekleşip gerçekleşmeyeceğini izlemelerini sağlayacaktır. Böylece öykü bitimine kadar dikkatlerinin dağılması önlenebilecektir. Çocukların okuma öncesinde yaptıkları tahminler yetişkin tarafından dikkatle dinlenilmeli ve genişletilerek ve yeniden düzenlenerek tekrar edilmelidir. Bu şekilde düşüncelerin uygun şekilde ifade edilmesi konusunda çocuklara model olunmaktadır. Sözgelimi, kitabın kapağındaki resme bakarak, "fare zıplıyor, mutlu" gibi bir ifade kullanan bir çocuğun bu cümlesi, "evet fare koltuğun üzerinde zıplıyor. Çünkü çok mutlu" şeklinde tekrar düzenlenerek ifade edilebilir. Böylece çocukların yeni sözcükleri ve dil bilgisel yapıları fark etmeleri sağlanacaktır. Öykü öncesinde kitabın başlığının yanı sıra yazarının, resimleyenin ve yayınevinin bilinmesi, gerek yazı farkındalığının gelişmesi, gerekse kitap kültürünün oluşması açısından büyük önem taşımaktadır. Bu amaçla, kitabın yazarının, resimleyeninin ve yayınevinin isimleri öykü öncesinde okunmalı ve aynı zamanda parmakla gösterilmelidir. Bütün çocukların rahatça görebileceği şekilde gerçekleşen bu uygulamaların ardından çocuklara kitapta geçen öyküyü dikkatlice dinlemeleri söylenmeli ve bütün çocukların rahatlıkla duyabilecekleri şekilde sesli olarak öykü okunmaya başlanmalıdır.

Okuma sırasında EKO uygulama adımları. EKO sırasında öyküdeki anlamı bilinmeyen sözcüklerin açıklanması büyük önem taşımaktadır. Bu sözcükler kimi zaman yetişkin tarafından okuma öncesinde belirlenen hedef sözcükler olabileceği gibi, kimi zaman da okuma sırasında çocuklar tarafından anlamı sorulan sözcükler olabilmektedir. $\mathrm{Bu}$ nedenle yetişkin, öykünün okunması sırasında çocuklardan gelebilecek sorulara karşı hazırlıklı olmalı, sözcüklerin anlamlarını açıklarken çocuk dostu terimler kullanmalıdır. Ayrıca, öğretilmesi 
hedeflenen sözcüklerin kitaptaki resimleri çocuklara gösterilmeli, çocukların bu resimlere dokunmalarına, birbirlerine göstermelerine izin verilmelidir. Hedef sözcüklerin resimleri kitapta yer almıyorsa ya da yeterince açık bir şekilde görülmüyorsa, yetişkin ek materyaller kullanarak- sözgelimi "kaplumbağa" hedef sözcügünün resmi kitapta açık bir şekilde görülmüyorsa, bir su kaplumbağasını sınıfa getirerek, oyuncak bir kaplumbağa ya da kaplumbağa resminin yer aldığı bir nesne kartını kullanarak- bu sözcüklerin anlaşılırlığını artırmalıdır. Bu tür bir yaklaşım, bilişsel olarak işlem öncesi dönemde olan okul öncesi dönem çocuklarının somut yaşantılardan yola çıkarak öğrenmelerini destekleyecek, öğrenmenin kalıcılığını sağlayabilecektir. Öğrenilenlerin kalıcılığının sağlanmasında, öğrenilen yeni bilginin işlevsel olmasının ve bireyin kendi yaşantısı ile ilişkili olmasının önemli olduğu bilinmektedir. Bu bağlamda EKO uygulamaları sırasında, hedef sözcükler ile çocukların kendi yaşamları arasında bağlantı kurmalarını sağlayacak örnekler verilmesi ve çocukların da açık uçlu sorular yardımıyla hedef sözcüklere yönelik olarak kendi örneklerini vermelerinin teşvik edilmesi esastır. Böylece hedef sözcüklerin anlamlarının çocuklar tarafından öğrenilmesi desteklenmektedir. Ayrıca, yeri geldikçe hedef sözcüklerin ve anlamlarının öykü içinde tekrarlanması, hedef sözcüklerin resimlerinin gösterilmesinin ve çocuklar tarafından hedef sözcüklerin anlamlarının tekrarlanmasının istenmesi de hem çocukların dikkatlerini toplamalarına yardımcı olmakta, hem de hedef sözcüklerin ve anlamlarının pekişmesini sağlamaktadır. Öykü okuma sırasında çocuklara yeni okunan öykü ile daha önce okunmuş olan bir öykü arasında bağlantı kurmalarını sağlayacak sorular sorulması da yeni öğrenilen sözcüklerin pekiştirilmesini ve var olan bilgilerin etkin hale getirilmesini sağlayıcı yollar arasında yer almaktadır.

EKO, yukarıda da değinildiği üzere, erken okuryazarlık becerilerinin desteklenmesinde etkili bir uygulamadır. Bu bağlamda, erken okuryazarlık becerileri arasında yer alan ve gelecekteki okuma yazma becerileri ile ilişkili olduğu çok sayıda araştırma ile ortaya konan sesbilgisel farkındalık becerilerinin de EKO uygulamaları aracılığıyla desteklenmesi mümkündür. Okuma öncesinde belirlenen hedef sesbirimlerin okuma sırasında uygun olan yerlerde vurgulanması (sözgelimi, hedeflenen sesbirime sözcük başında çocukların dikkatlerinin çekilmesi, öyküde aynı sesle başlayan başka sözcüklerin gösterilmesi vb.) ve hedef sözcüklerin sesbilgisel olarak kodlanması (sözcükleri oluşturan sesbirimlerin tek tek sesletiminin yapılması) sesbilgisel farkındalık becerilerinin kazanımına katkı sağlayacaktır. Bununla birlikte, çocuklardan bu kodlamaları tekrarlamalarının istenmesi çocukların sözcüklerin sesbilgisel organizasyonunu fark etmelerine ve bu beceriyi diğer sözcüklere de uygulamalarına yardımcı olacaktır.

Açık uçlu soruların sorulması EKO’nun temel uygulama ilkelerinden biridir. Yanıtı “evet/hayır” olan sorulara kıyasla açık uçlu sorular, çocukların daha fazla sayıda sözcükle ve daha gelişmiş dil yapılarını kullanarak düşüncelerini ifade etmelerine yardımcı olmakta, yetişkin tarafından çocuklara öykü okuma sırasında sunulan dil bilgisel modellerin pekiştirilmesini sağlamaktadır. Öykü ile ilgili çocuklara "kim, ne, nerede, ne zaman" ve "niçin" sorularını sorarken okunan öykünün akışını bozmayacak bir düzen izlenmesinde yarar vardır. Açık uçlu sorulardan bazılarının çocukların olayların akışı ve sonucu hakkında tahminde bulunmalarını sağlayacak nitelikte olmaları önemlidir. Böylece çocuklar bir yandan öykünün giriş, gelişme ve sonuç gibi yapısal özelliklerinin farkına varırken, bir yandan da düşüncelerini etkili bir şekilde ifade etme yollarını keşfedebileceklerdir. Bu süreçte yetişkin, çocuklardan gelen yanıtları dikkatle dinlemeli, değerlendirmeli ve onların yanıtlarını tekrarlayarak, genişletmeler yoluyla çocukların kullandıkları dil bilgisel yapıları çeşitlendirmelidir. Ayrıca, çocukları verdikleri yanıtlar ve katılımları için sözel olarak ödüllendirmek çocukların EKO çalışmalarına daha istekle katılmasını sağlamakta, soru sormak için onları cesaretlendirmekte ve hedef sözcüklerin farklı kullanımlarının pekiştirilmesine yardımcı olmaktadır. EKO’da, dil becerilerinin desteklenmesi amacıyla çocukların kitaptaki bir resme bakarak, resimde geçen olayları tanımlamaları da istenmektedir. Bu amaçla, okuma sırasında çocukların kitaptaki resimlere dokunmalarına ve incelemelerine izin verilmekte, açık uçlu sorular aracılığıyla düşüncelerini ifade etmeleri sağlanmaktadır.

EKO'da çocukların ifade edici ve alıcı dil becerilerinin desteklenebilmesi için yeni öğrenme fursatları yaratılmalı ve var olan öğrenme firsatları değerlendirilmelidir. Öykü okunurken zaman zaman durup, çocuklardan yarım bırakılan cümleyi tamamlamalarını istemek çocukların alıcı ve ifade edici dil sözcük 
dağarcıklarını etkin bir şekilde kullanmalarını sağlayan stratejilerden biridir. Bu noktada, okunan öykünün çok iyi analiz edilmesi gerektiğini vurgulamakta yarar vardır. Bu tür çalışmalar, öykünün akışını bozmayacak şekilde, dilbilgisel açıdan anlamlı bir biçimde gerçekleştirilmeli ve cümlelerin belirlenmesinde resimlerin yeterince ipucu sağladığı ya da tekrarlı cümlelerin bulunduğu bölümler tercih edilmelidir.

Okuma sonrasında EKO uygulama adımları. EKO uygulamasında geleneksel öykü okuma çalışmaları ile benzer şekilde, okumanın hemen ardından çocukların öyküyü özetlemeleri istenmektedir. $\mathrm{Bu}$ noktada, katılımcı bütün çocukların öykünün özetine katkıda bulunmalarının sağlanması önem taşımaktadır. Bu amaçla, kimi zaman öykünün resimleri tekrar gösterilerek hatırlatmalar yapılmakta, kimi zaman açık uçlu sorular yardımıyla (Sonra ne olmuştu? Oraya gitmeden önce başka bir yere daha gitmişti, hatırlıyor musunuz? vb.) çocukların olayların sırasını hatırlamalarına yardımcı olunmaktadır. Ayrıca, öykünün gerçek olup olmadığını yönünde sorular sorulmakta (Peki sizce gerçekten böyle bir şey olabilir mi? Neden? vb.) ve çocuklardan öykü için yeni bir son oluşturmaları da (Öykünün nasıl bitmesini isterdiniz? Neden? / Öykü sizce başka nasıl bitebilirdi? Neden? / .... olsaydı ne olurdu? vb.) istenmektedir. Böylece, çocukların yaratıcılıklarını kullanarak düşüncelerini ifade etmeleri sağlanmaktadır.

EKO'da okuma öncesinden başlayarak, her basamakta sistematik ve planlı bir yaklaşım izlenmektedir. Çocukların liderliğini izleyerek etkileşimin sürdürülmesini temel alan EKO, çocukların birbirleri ile de sözel (birbirlerine soru sorma ve yanıt verme gibi) ve sözel olmayan yollarla (birbirlerine kitaptaki resimleri gösterme vb.) iletişim kurmalarını teşvik etmektedir. Bu özellikleriyle EKO yetişkin-çocuk ve çocuk- çocuk arasında etkin bir etkileşime dayalı olarak gerçekleştirilen bir okuma sürecini içermektedir. Bu süreç içinde okuma öncesi ve okuma sırasındaki etkileşime dayalı davranışlar kadar, okuma sonrasında gerçekleştirilmesi gereken davranışlar da önem taşımaktadır. Bu bağlamda okuma sonrasında sınıf içinde gerçekleştirilecek farklı etkinlikler yardımıyla (drama, müzik ve diğer öğrenme merkezlerinde gerçekleştirilecek etkinlikler aracılı̆̆ıyla) okunan öyküde yer alan hedef sözcükler ve sesbirimlerin, yeni öğrenilen kavramların pekiştirilmesi ve bu yolla günlük eğitim akışına yerleştirilmesi mümkündür. 


\section{Kaynaklar}

Aarnoutse, C., Van Leeuwe, J., \& Verhoeven, L. (2005). Early literacy from a longitudinal perspective. Educational Research and Evaluation, 11(3), 253-275.

Armbruster, B. B., Lehr, F., \& Osborn, J. (2003). Put reading first: The research building blocks for teaching children to read: Kindergarten through grade 3. Jessup, MD: National Institute for Literacy.

Arnold, D. H., Lonigan, C. J., Whitehurst, G. J., \& Epstein, J. N. (1994). Accelerating language development through picture-book reading. Journal of Educational Psychology, 86(2), 235-243.

Badian, N. A. (1995). Predicting reading ability over the long term: The changing roles of letter-naming, phonological awareness and orthographic processing. Annals of Dyslexia, 45(1), 79-96.

Beck, I. L., McKeown, M. G., \& Kucan, L. (2002). Bringing words to life: Robust vocabulary instruction. New York: Guilford Press.

Bursuck, W., \& Damer, M. (2007). Reading instruction for students who are at risk or have disabilities. Boston, MA: Pearson Education, Inc.

Casey, A., \& Howe, K. (2002). Best practices in early literacy skills. In A. Thomas \& J. Grimes (Eds.), Best practices in school psychology IV (pp. 721-735). Bethesda, MD: NASP.

Cunningham, E. A., \& Stanovich, E. K. (1997). Early reading acquisition and its relation to reading experience and ability 10 years later. Developmental Psychology, 33(6), 934-945.

Çakmak, T., \& Yılmaz, B. (2009). Okul öncesi dönem çocuklarının okuma alışkanlığına hazırlık durumları üzerine bir araştırma: Hacettepe Üniversitesi Beytepe Anaokulu örneği. Türk Kütüphaneciliği, 23(3), 489-509.

Denton, K., \& West, J. (2002). Children's reading and mathematics achievement in kindergarten and first grade. (U.S. Department of Education, NCES 2002-125). Washington, DC: U.S. Government Printing Office.

Dickinson, D. K., \& McCabe, A. (2001). Bringing it all together: The multiple origins, skills and environmental supports of early literacy. Learning Disabilities Research and Practice, 16(4), 186-202.

Dickinson, D., \& Tabors, P. (2001). Beginning literacy with language: Young children learning at home and school. Baltimore: Paul H. Brookes.

Elliott, E., \& Olliff, C. (2008). Developmentally appropriate emergent literacy activities for young children: Adapting the Early Literacy and Learning Model (ELLM). Early Childhood Education Journal, 35(6), 551-556.

Ergül, C., Akoğlu, G., Sarıca, A. D., Karaman, G., Tufan, M., Bahap-Kudret, Z., et al. (2016). An adapted dialogic reading program for Turkish kindergarteners from low socio-economic backgrounds. Journal of Education and Training Studies, 4(7), 169-184.

Ezell, H. K., \& Justice, L. M. (2000). Increasing the print focus of adult-child shared book reading through observational learning. American Journal of Speech Language Pathology, 9(1), 36-47.

Fleury, U. P., Miramontez, S. H., Hudson, R. F., \& Schwartz, I. S. (2014). Promoting active participation in book reading for preschoolers with Autism Spectrum Disorder: A preliminary study. Child Language Teaching and Therapy, 30(3), 273-288. 
Foorman, B. R., Francis, D. J., Fletcher, J. M., Schatschneider, C., \& Mehta, P. (1998). The role of instruction in learning to read: Preventing reading disabilities in at-risk children. Journal of Educational Psychology, 90(1), 37-55.

Greene, B. E., \& Lynch-Brown, C. (2002). Effects of teachers' reading aloud styles on vocabulary acquisition and comprehension of students in the early elementary grades. Journal of Educational Psychology, 94(3), 465-473.

Griffith, P., \& Olson, M. W. (1992). Phonemic awareness helps beginning readers break the code. Reading Teacher, 45(7), 516-523.

Hargrave, A. C., \& Senechal, M. (2000). A book reading intervention with preschool children who have limited vocabularies: The benefits of regular reading and reading. Early Childhood Research Quarterly, 15(1), 75-90.

Hart, B., \& Risley, T. (2003). The early catastrophe. American Educator, 27(4), 6-9.

Huebner, C. E., \& Payne, K. (2010). Home support for emergent literacy: Follow-up of a community-based implementation of dialogic reading. Journal of Applied Developmental Psychology, 31(3), 195-201.

Huennekens, M. E., \& Xu, Y. (2016). Using dialogic reading to enhance emergent literacy skills of young dual language learners. Early Childhood Development and Care, 186(2), 324-340.

Juel, C. (1988). Learning to read and write: A longitudinal study of fifty-four children from first through fourth grade. Journal of Educational Psychology, 80, 437-447.

Justice, L. M., \& Ezell, H. (2002). Use of storybook reading to increase print awareness in at risk children. American Journal of Speech-Language Pathology, 11(1), 17-29.

Justice, L. M., \& Pullen, P. C. (2003). Promising interventions for promoting emergent literacy skills: Three evidence-based approaches. Topics in Early Childhood Special Education, 23(3), 99-113.

Justice, L. M., Kaderavek, J., Bowles, R. P., \& Grimm, K. J. (2005). Language impairment, parent-child shared reading, and phonological awareness. Topics in Early Childhood Special Education, 25(3), 143-156.

Justice, L., Invernizzi, M., Geller, K., Sullivan, A., \& Welsch, J. (2005). Descriptive-developmental performance of at-risk preschoolers on early literacy tasks. Reading Psychology, 26(1), 1-25.

Kotaman, H. (2008). Impacts of dialogical storybook reading on young children's reading attitudes and vocabulary development. Reading Improvement, 45(2), 55-61.

Kush, J. C., Watkins, M. W., \& Brookhart, S. M. (2005). The temporal-interactive influence of reading achievement and reading attitude. Educational Research and Evaluation, 11(1), 29-44.

LaCour, M. M., McDonald, C., Tissington, L. D., \& Thomason, G. (2013). Improving pre-kindergarten children's attitude and interest in reading through a parent workshop on the use of dialogic reading techniques. Reading Improvement, 50(1), 1-11.

Lesiak, J. L. (1997). Research-based answers to questions about emergent literacy in kindergarten. Psychology in the Schools, 34(2), 143-160.

Lever, R., \& Senechal, M. (2011). Discussing stories: On how a dialogic reading intervention improves kindergartners' oral narrative construction. Journal of Experimental Child Psychology, 108(1), 1-24.

Lomax, R., \& McGee, L. (1987). Young children's concepts about print and reading: Toward a model of word reading acquisition. Reading Research Quarterly, 22(2), 237-256. 
Lonigan, C. J., \& Whitehurst, G. J. (1998). Relative efficacy of parent and teacher involvement in a sharedreading intervention for preschool children from low-income backgrounds. Early Childhood Research Quarterly, 13(2), 263-290.

Lundberg, L., Frost, J., \& Peterson, O. (1988). Effects of an extensive program for stimulating phonological awareness in preschool children. Reading Research Quarterly, 23(3), 263-284.

Maclean, M., Bryant, P., \& Bradley, L. (1987). Rhymes, nursery rhymes, and reading in early childhood. Merrill-Palmer Quarterly, 33(3), 255-281.

McCardle, P., Scarborough, H. S., \& Catts. H. W. (2001). Predicting, explaining, and preventing reading difficulties. Learning Disabilities Research and Practice, 16(4), 230-239.

Morgan, P., \& Meier, C. R. (2008). Dialogic reading's potential to improve children's emergent literacy skills and behavior. Preventing School Failure, 52(4), 11-16.

Nelson, P. A. (2005). Could you and your students use a poetry get away? The Reading Teacher, 58(8), 771-773.

Neuman, S. B., \& Dickinson, D. K. (Eds.). (2001). Handbook of early literacy research. New York: Guilford Publications.

Niklas, F., \& Schneider, W. (2013). Home literacy environment and the beginning of reading and spelling. Contemporary Educational Psychology, 38(1), 40-50.

Pullen, P. C., \& Justice, L. M. (2003). Enhancing phonological awareness, print awareness, and oral language skills in preschool children. Intervention in School and Clinic, 39(2), 87-98.

Raz, I. S., \& Bryant, P. (1990). Social background, phonological awareness, and children's reading. British Journal of Developmental Psychology, 8(3), 209-225.

Riley, J. L. (1996). The ability to label the letters of the alphabet at school entry: A discussion on its value. Journal of Research in Reading, 19(2), 87-101.

Robbins, C., \& Ehri, L. C. (1994). Reading storybooks to kindergartners helps them learn new vocabulary words. Journal of Educational Psychology, 86(1), 54-64.

Rush, K. L. (1999). Caregiver-child interactions and early literacy development of preschool children from lowincome environments. Topics in Early Childhood Special Education, 19(1), 3-14.

Scarborough, H. S. (2001). Connecting early language and literacy to later reading (dis)abilities. In Neuman, S. B., \& Dickinson, D. K. (Eds.), Handbook of early literacy research (pp. 97-110). New York, NY: Guilford Press.

Senechal, M. (1997). The differential effect of storybook reading on preschoolers' acquisition of expressive and receptive vocabulary. Journal of Child Language, 24(1), 123-138.

Senechal, M., \& Cornell, E. H. (1993). Vocabulary acquisition through shared reading experiences. Reading Research Quarterly, 28(4), 360-374.

Senechal, M., LeFevre, J., Thomas, E., \& Daley, K. (1998). Differential effects of home literacy experiences on the development of oral and written language. Reading Research Quarterly, 33(1), 96-116.

Senechal, M., Thomas, E., \& Monker, J. (1995). Individual differences in 4-year-old children's acquisition of vocabulary during storybook reading. Journal of Educational Psychology, 87(2), 218-229. 
Sim, S. S. H., Berthelsen, D., Walker, S., Nicholson, J. M., \& Fielding-Barnsley, R. (2014). A shared reading intervention with parents to enhance young children's early literacy skills. Early Child Development and Care, 184(11), 1531-1549.

Snow, C. E., Burns, M. S., \& Griffin, P. (Eds.). (1998). Preventing reading difficulties in young children. Washington DC: National Academy Press.

Sperling, A. R., \& Head, M. D, (2002). Reading attitudes and literacy skills in prekindergarten and kindergarten children. Early Childhood Education Journal, 29(4), 233-236.

Spira, E. G., Bracken, S. S., \& Fischel, E. J. (2005). Predicting improvement after first-grade reading difficulties: The effects of oral language, emergent literacy, and behavior skills. Developmental Psychology, 41(1), 225-234.

Stevenson, J., \& Fredman, G. (1990). The social environmental correlates of reading ability. Journal of Child Psychology and Psychiatry, 31(5), 681-698.

Sulzby, E., \& Teale, W. (1991). Emergent literacy. In R. Barr, M. L. Kamil, P. B. Mosenthal, \& P. D. Pearson (Eds.), Handbook of reading research (Vol. 2, pp. 727-757). New York: Longman.

Şimşek, Z. E., \& Işıkoğlu-Erdoğan, N. (2015). Effects of the dialogic and traditional reading techniques on children's language development. Procedia-Social and Behavioral Sciences, 197, 754-758.

Towson, J., \& Gallagher, P. A. (2016). Dialogic reading for young children with disabilities: A review of literature with suggestions for future research. Başkent University Journal of Education, 3(1), 58-71.

Uzuner, Y. (1997, Ekim). Filizlenen okur-yazarlık. Okul Öncesi Dönemde Özel Eğitim Semineri, Ankara.

Valdez-Menchaca, M. C., \& Whitehurst, G. J. (1992). Accelerating language development through picture book reading: A systematic extension to Mexican day-care. Developmental Psychology, 28(6), 1106-1114.

Whitehurst, G. J., \& Lonigan, C. (2001). Emergent literacy: Development from prereaders to readers. In S. Neuman \& D. Dickinson (Eds.), Handbook of early literacy research (pp. 11-30). New York: Guilford.

Whitehurst, G. J., \& Lonigan, C. J. (1998). Child development and emergent literacy. Child Development, 69(3), 848-872.

Whitehurst, G. J., Arnold, D. S., Epstein, J. N., Angell, A. L., Smith, M., \& Fischel, J. E. (1994). A picture book reading intervention in day care and home for children from low-income families. Developmental Psychology, 30(5), 679-689.

Whitehurst, G. J., Epstein, J. N., Angell, A. L., Payne, A. C., Crone, D. A., \& Fischel, J. E. (1994). Outcomes of an emergent literacy intervention in Head Start. Journal of Educational Psychology, 86(4), 542-555.

Whitehurst, G. J., Falco, F. L., Lonigan, C., Fischel, J. E., DeBaryshe, B. D., Valdez-Menchaca, M. C., et al. (1988). Accelerating language development through picture book reading. Developmental Psychology, 24(4), 552-558.

Yopp, H. K., \& Yopp, R. H. (2000). Supporting phonemic awareness development in the classroom. The Reading Teacher, 54(2), 130-143. 


\title{
Summary
}

\section{Dialogic Reading: An Effective Method to Improve Language and Early Literacy Skills*}

\author{
Cevriye Ergül ${ }^{* *}$ \\ Ankara University
}

\author{
Ayşe Dolunay Sarıca*** \\ Dokuz Eylül University
}

\author{
Gözde Akoğlu**** \\ Kırıkkale University
}

\begin{abstract}
Early literacy is defined as "the knowledge, skills and attitudes children are expected to display prior to formal reading and writing instruction” (Sulzby \& Teale, 1991; Uzuner, 1997; Whitehurst \& Lonigan, 1998) and is considered one of the strongest predictors of reading performance. Early literacy includes verbal language, vocabulary, phonological awareness, print awareness and letter knowledge (Aarnoutse, Leeuwe, \& Verhoeven, 2005; Casey \& Howe, 2002; Dickinson \& McCabe, 2001; Elliott \& Olliff, 2008; Neuman \& Dickinson, 2001; Spira, Bracken, \& Fischel, 2005; Whitehurst \& Lonigan, 2001).

Research indicates that early literacy skills that are found have short and long term effects on school performance be supported during the preschool period. Adult-child shared book reading activities in home and school environments is one of the most widely used techniques for supporting the early literacy skills of preschoolers. Studies show that children who attend shared book reading with an adult on a routine basis display higher performance on expressive language and vocabulary domains compared to their peers (Armbruster, Lehr, \& Osborne, 2003; Beck, McKeown, \& Kucan, 2002; Greene \& Lynch-Brown, 2002; Hart \& Risley, 2003; Huebner \& Payne, 2010; Robbins \& Ehri, 1994). It is believed that shared book reading provides an excellent context for acquiring new words (Senechal \& Cornell, 1993) and that repeated readings help children acquire new words in case they fail to acquire them in single readings (Robbins \& Ehri, 1994).

Besides repeated reading sessions, some studies show that adult instructive strategies during shared reading enhances children's language skills even to a higher degree (Robbins \& Ehri, 1994; Senechal \& Cornell, 1993; Senechal, LeFevre, Thomas, \& Daley, 1998) in that, children who answer questions regarding the target

\footnotetext{
*This study was supported by Grant 111K161 from The Scientific and Technological Research Council of Turkey.

${ }^{* *}$ Corresponding Author: Assoc. Prof. Dr., Ankara University, Faculty of Educational Sciences, Department of Special Education, Ankara, E-mail: cergul@ankara.edu.tr

${ }^{* * *}$ Assist. Prof. Dr., Dokuz Eylül University, Buca Faculty of Education, Department of Special Education, İzmir, E-mail: dolunaysarica@gmail.com

${ }^{* * * * *}$ Assoc. Prof. Dr., Kırıkkale University, Faculty of Health Sciences, Department of Child Development, Kırıkkale, E-mail: gakoglu@kku.edu.tr
} 
words in the story learn and produce more words compared to their peers who only repeat those target words and point to their pictures (Senechal, 1997; Senechal, Thomas, \& Monker, 1995). These findings imply that active participation of the child as well as increased adult-child interaction during shared reading seems to boost child learning.

Dialogic Reading developed by Whitehurst and colleagues (Whitehurst et al., 1988; Whitehurst, Arnold et al., 1994; Whitehurst, Epstein et al., 1994) was based on the aforementioned findings in the literature. Dialogic Reading (DR) ia a method aiming to enhance the verbal language skills and word knowledge of preschoolers by a dialogic interaction between a child and an adult in a book reading context (Whitehurst et al., 1988; Whitehurst, Arnold et al., 1994; Whitehurst, Epstein et al., 1994). During DR, the adult and the child exchange roles and the child learns to be the story reader with the support of the adult. The role of the adult during this process is to be an active listener and a questioner. The adult provides opportunities for the child to talk by asking questions about the story, defines unknown words and repeats and expands child's verbal responses (Justice \& Pullen, 2003; Whitehurst, Arnold et al., 1994).

DR stands on three principles that aim to develop children's receptive and expressive language skills. These are encouraging the child to participate in the reading activity, provide feedback on her speech and select boks that reflect the child's interests (Hargrave \& Senechal, 2000; Justice \& Pullen, 2003; Morgan \& Meier, 2008). These strategies support the child's interest in the story, listening comprehension, vocabulary and proper use of language. The child's active involvement in reading is achieved through certain techniques to encourage child initiated talk.

Many studies have investigated the language effects of DR on preschoolers with various developmental characteristics. These intervention studies conducted with preschoolers with normal development, children at risk (such as children from economically disadvantaged families or with dual language) and/or children with developmental disabilities (including children with autism and language disorders) showed that DR had significant positive effects on the language (especially expressive) skills of those children and these results were achieved mainly through a 6-8 week intervention in home, school or home+school conditions (Lonigan \& Whitehurst, 1998; Whitehurst et al., 1994). Other more recent studies have also confirmed these findings for preschoolers with and without developmental risks and disabilities (e.g. children with dual language, language delay, autism) (Fluery, Miramontez, Hudson \& Schwartz, 2014; Hargrave \& Senechal, 2000; Huennekens \& Xu, 2016; Lever \& Senechal, 2011; Sim, Berthelsen, Walker, Nicholson \& Fielding-Barnsley, 2014; Şimşek \& Iş1loğlu-Erdoğan, 2015; Towson \& Gallagher, 2016).

Taken together, findings from studies on the effects of DR generally have made way for many educators to use DR as an evidence based technique for enhancing the language and early literacy skills of their preschoolers (Justice \& Pullen, 2003). Therefore, it may be safe to claim that DR is an effective, ageappropriate, used friendly technique that may easily be integrated into daily routines of adults and preschoolers. Inspired by the above findings, the authors tested the effectiveness of DR on the language and early literacy skills of a group of Turkish preschoolers from low socio-economic backgrounds through a Project funded by the Scientific and Technological Research Council of Turkey. The findigs of this study confirmed the DR literature such that, preschoolers in the treatment conditions (home, school, home+school) scored significantly higher on the language and early literacy tests in preschool (Ergül et al., in press) and reading performance in first grade compared to the control group (Ergül et al., in press). Based on these findings, this paper aimed to introduce DR as an effective method of shared book reading as it was implemented in their original study.

\section{Önerilen Attf Sekli}

Ergül, C., Sarıca, A. D., \& Akoğlu, G. (2016). Etkileşimli kitap okuma: Dil ve erken okuryazarlık becerilerinin geliştirilmesinde etkili bir yöntem. Ankara Üniversitesi Eğitim Bilimleri Fakültesi Özel Eğitim Dergisi, 17(2), 193-206. 